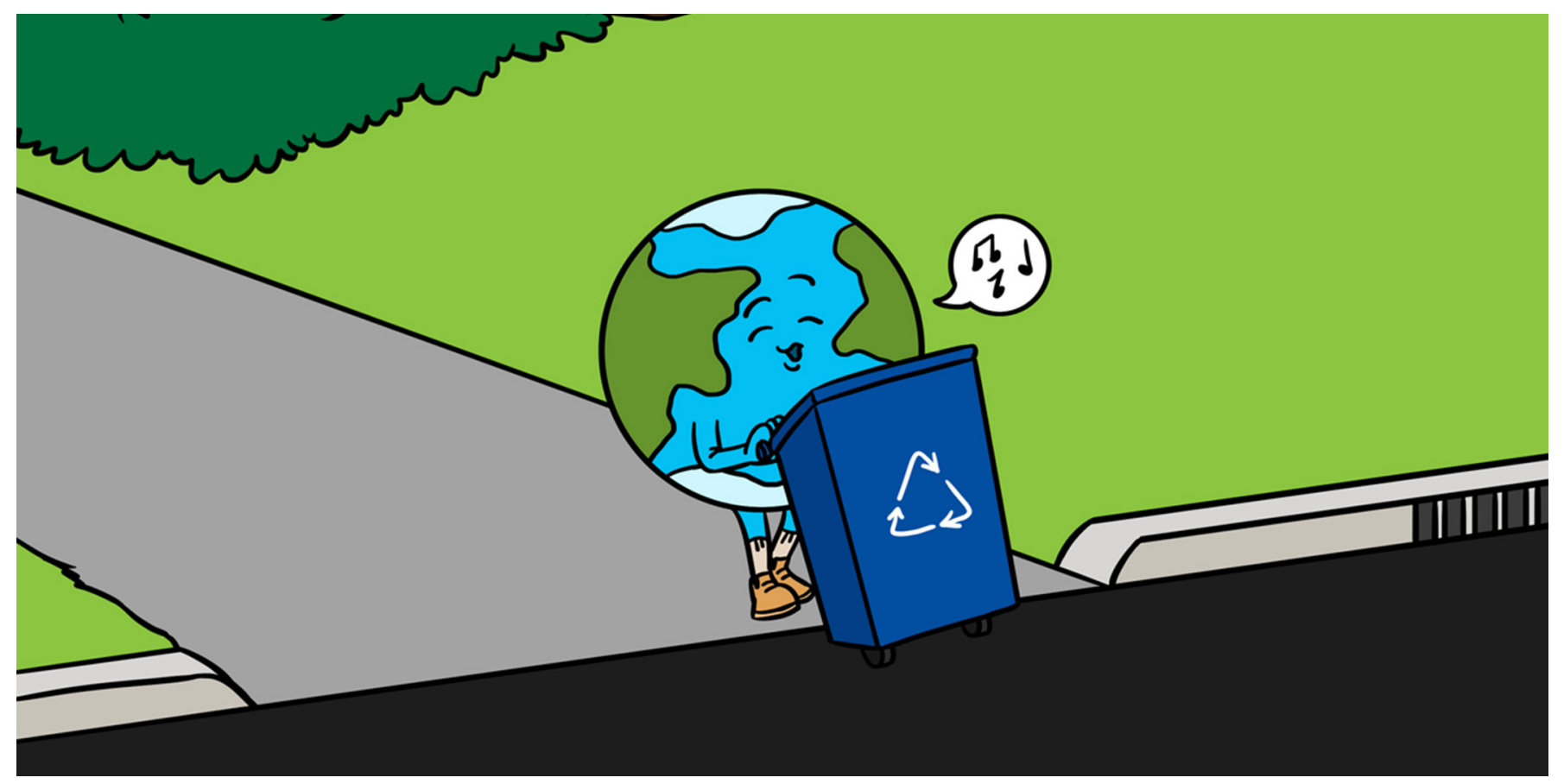

\title{
HOW THE EARTH RECYCLES
}

Christine Newville ${ }^{1 *}$, Donna L. Whitney ${ }^{1}$, Patricia Kang ${ }^{1}$, Natalie H. Raia ${ }^{1}$ and Katherine F. Fornash ${ }^{2}$

${ }^{1}$ Department of Earth \& Environmental Sciences, University of Minnesota, Minneapolis, MN, United States

${ }^{2}$ Department of Geological Sciences, Ohio University, Athens, $\mathrm{OH}$, United States

\section{YOUNG REVIEWERS:}

HEIDI

AGE: 14

MAYA

AGE: 13
Recycling is not just for plastic. Did you know that the Earth recycles? Recycling happens because the outer part of the planet is made up of large moving pieces of rock. Some of these pieces, called tectonic plates, sink deep down into the Earth. The deeper they go, the more heat and pressure they experience. This causes chemical reactions, including melting of the minerals that make up the rocks. Elements and water trapped inside the melting minerals are released and erupt from volcanoes, returning to the surface. The Earth has recycled! In this article, we present new research on a mineral called lawsonite. Lawsonite only forms in plates that dive into the Earth. Lawsonite has returned to the Earth's surface in a few rare places where we can collect and analyze it. The composition of elements inside the lawsonite mineral help us understand the deep part of the Earth recycling system.

\section{HOW DOES THE EARTH RECYCLE ELEMENTS?}

The rocks that make up our planet may seem old and indestructible. However, given enough time, they change and break down. Rocks 
METAMORPHISM

A change in the minerals, texture, or composition of a solid rock. This process may occur due to pressure or temperature changes or the introduction of water or other fluids.

\section{TECTONIC PLATE}

A large slab of solid rock that floats on top of Earth's mantle. Tectonic plates form the world's continents and oceans and are between 15 and 200 $\mathrm{km}$ thick.

RIFT

A linear gap in oceanic or continental crust where tectonic plates move apart.

\section{SUBDUCTION}

The process by which one tectonic plate sinks below another plate.

\section{LAWSONITE}

A metamorphic mineral that forms in subduction zones. It contains high amounts of water and the elements $\mathrm{Ca}, \mathrm{Al}, \mathrm{Si}, \mathrm{O}$, and small amounts of other elements. are like chocolate chip cookies. Cookies (and rocks) are made of various ingredients. A cookie contains chocolate chips, sugar, flour, and salt. These can be compared to the minerals that make up rocks. The minerals are made of elements. Think of it like this: elements (such as oxygen, carbon, sodium) make up minerals (flour, sugar, salt, chocolate chips) which make up rocks (chocolate chip cookies). The minerals in a rock change when heated, just as cookie batter changes when you bake it. Other changes happen when minerals react with hot water or are squeezed at high-pressure conditions. In nature, this change is called metamorphism. If you could watch a mineral for millions or billions of years, you would see these changes. You would need more than time, though. The Earth's recycling system is difficult to see because it occurs deep underground. To observe it, you would need to be able to see under the oceans and into the ground, because many of the changes happen inside the Earth.

Recycling occurs because our planet is in motion. The Earth is covered in large moving pieces, called tectonic plates. Sometimes these are just called plates. The crust of continents and oceans is the top part of these plates. Plates can move toward each other or away from each other, and both types of plate motion drive the planet's recycling system. How does it work? Where plates move apart, the gap, called a rift, is filled by hot rocks and lava that rise up from below. Where two plates move toward each other, the older, denser plate will dive under the other. This is called subduction. This cycle of formation (at rifts) and destruction (subduction) of plates renews the Earth's supply of minerals, water, and other essential materials. This takes many millions of years, so humans can never see the whole recycling process.

Subduction can be seen as a "factory" because raw materials (minerals) go in, the Earth works on them, and then something different comes out (Figure 1) [1, 2]. The process starts under the oceans, where the raw material of the "factory" is formed at rifts in a plate. In the rift, new rock is created and added to the plate. When the plate eventually becomes old and dense, it subducts into the Earth, where minerals are buried and heated (metamorphosed) until they break down. When the minerals break down, they release trapped water and other elements. Some minerals in the rocks melt. These products of the "factory" make their way back to the Earth's surface in melted rock and gases.

One way to study this recycling process is to analyze the lava and gases erupted by volcanoes. Another way is to find rocks that were subducted and then brought back to the surface. These rocks escaped melting and other breakdown processes. The minerals in these rocks contain clues about the recycling process. We can analyze minerals that still contain water and other elements. One of the most useful minerals for investigating the subduction factory is lawsonite. Lawsonite is a water-rich mineral that only forms in subducting rocks. 
Figure 1

The features of a subduction zone. A tectonic plate with sediments and oceanic crust at its top dives below another tectonic plate. As the subducting rocks heat up, new minerals become stable. One of these new minerals is water-rich lawsonite. Some water-bearing minerals break down in subduction zones and release water, which causes melting in the hot mantle rocks above. This melted rock rises, erupts at volcanoes, and releases gases to the atmosphere. The elements in these materials then return to the ocean and oceanic crust, and the cycle repeats.

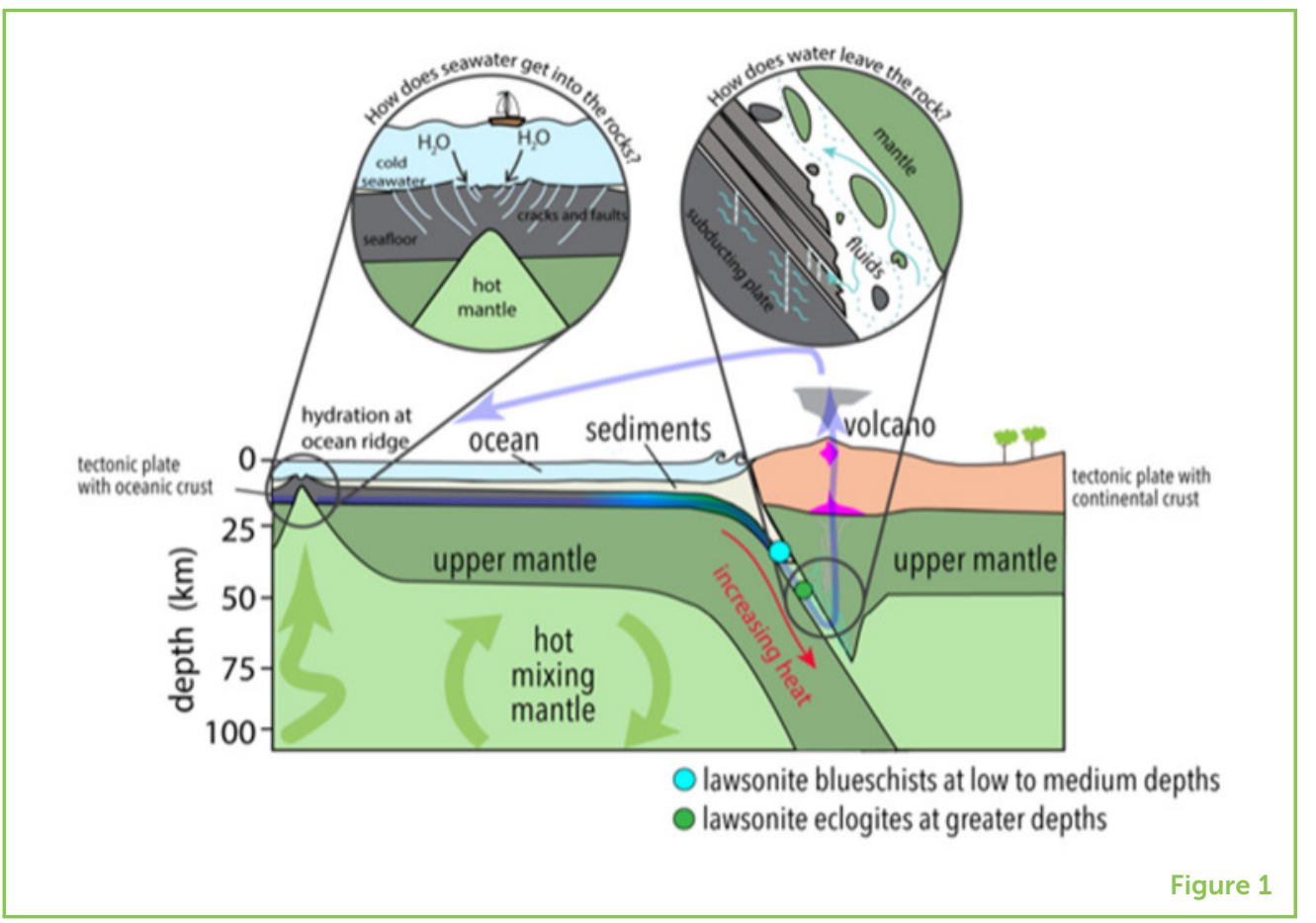

\section{STUDYING LAWSONITE TO LEARN ABOUT EARTH RECYCLING}

Newly-formed rocks in rifts deep in the ocean react with hot seawater, forming new minerals that contain water. Later, when these minerals are subducted, they undergo more reactions. This is how water-rich lawsonite forms during subduction (Figure 1). Lawsonite is important because it contains a lot of water and other important elements, including tiny amounts of uranium and lead. Each of these elements is important in Earth recycling, even in small amounts. Lawsonite carries these elements tens to hundreds of kilometers into the Earth. When lawsonite reacts with other minerals and starts to break down, it releases water and other elements. Water is the ingredient needed to melt the hot rocks that are above the subducting plate. This triggers the next step in the element recycling process, as magma (melted rock) transfers elements and water from the inside of the Earth to the surface. Since lawsonite is an important contributor to the Earth's recycling process, we can study it to understand how the deep parts of the "factory" work.

Geologists still do not know a lot about lawsonite because it is only stable in subducting plates. No other place in the world has the right combination of pressure and temperature for lawsonite to be stable. Also, lawsonite easily breaks down to form other minerals. So, despite its great abundance deep underground in subducting plates, we almost never see it in rocks at the Earth's surface [3, 4]. This is good for the planet, but not so good for geologists who want to study it! Fortunately, lawsonite does occur in some rocks, so we can 


\section{Figure 2}

To study rocks, geologists cut rock samples into rectangular pieces called billets. We glue the billet onto a glass slide and grind it down and polish it until the rock slice is so thin that light can pass through the minerals. Here are some

lawsonite-containing rocks, as they appear through a microscope. (A) A photo of an eclogite; (B) sketch of eclogite; (C) A photo of a blueschist; (D) sketch of blueschist. The various minerals contained in these rocks are listed in the key.

\section{ZONING}

Variation in the composition of a crystal of a mineral, resulting from changing conditions during its growth.

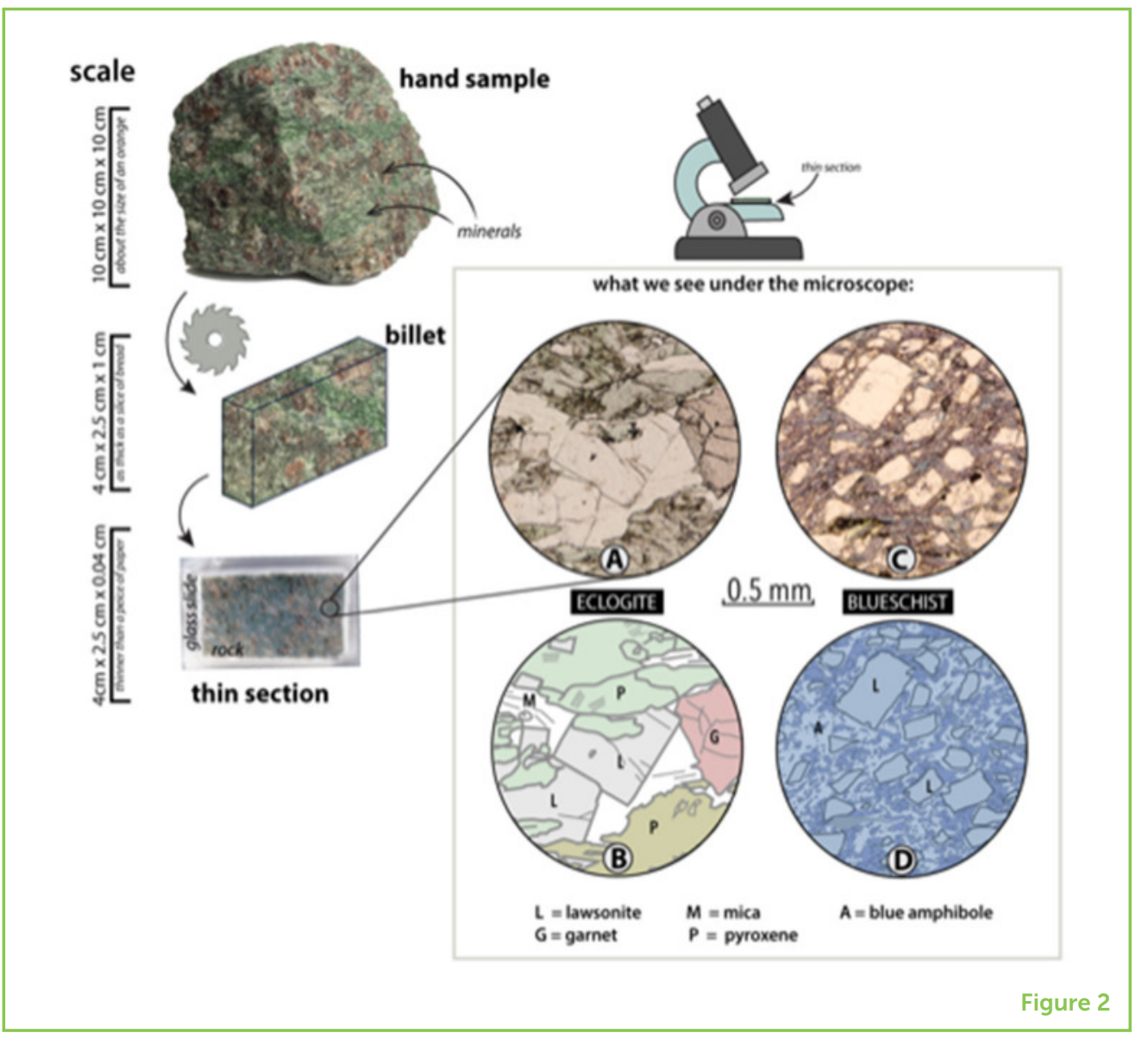

collect it and study it. Lawsonite mainly occurs in rocks from plates that were subducted to low or medium depths in the Earth. These rocks are called blueschists because they contain a distinctive blue mineral (Figure 2). Lawsonite can also occur in rocks called eclogite that form at greater depths (Figure 2). There are $<20$ places in the world where lawsonite occurs in the deep rocks [5], including Turkey, Corsica (France), British Columbia (Canada), the Dominican Republic, Guatemala, Australia, and the Alps. In addition, there is an interesting place in Arizona (USA) where pieces of lawsonite eclogite from a subducted plate have erupted from a now-extinct volcano.

\section{WHAT CAN WE LEARN FROM THE COMPOSITION OF LAWSONITE?}

As lawsonite forms, it inherits the elements of the rock it grows in. However, lawsonite can also change in composition as it grows. As a result, one part of the lawsonite crystal may have different amounts of particular elements than another part. This is called zoning. Like the tree rings that grow during the lifespan of a tree, mineral zoning provides a record of information about the chemical reactions, fluids, and elements involved in the recycling process. For example, zones resulting from different amounts of the element chromium in a 
Figure 3

Growth of a crystal of lawsonite during subduction. In stage 1 , a crystal grows from the elements around it. In stage 2, the elements available to feed the growing crystal have changed because the rock is at a different depth and temperature. Fluids help transport elements into or out of the rock. In stage 3 , the crystal keeps growing at greater depths, recording its changing environment. The false-color image, obtained with an electron microscope, shows variations in the element chromium $(\mathrm{Cr})$ in a lawsonite crystal. Red indicates higher amounts of $\mathrm{Cr}$, and green indicates lower amounts (Image modified from [5]).

\section{MANTLE}

A large volume of hot, dense rock that lies between the crust and the iron-rich core of the Earth.

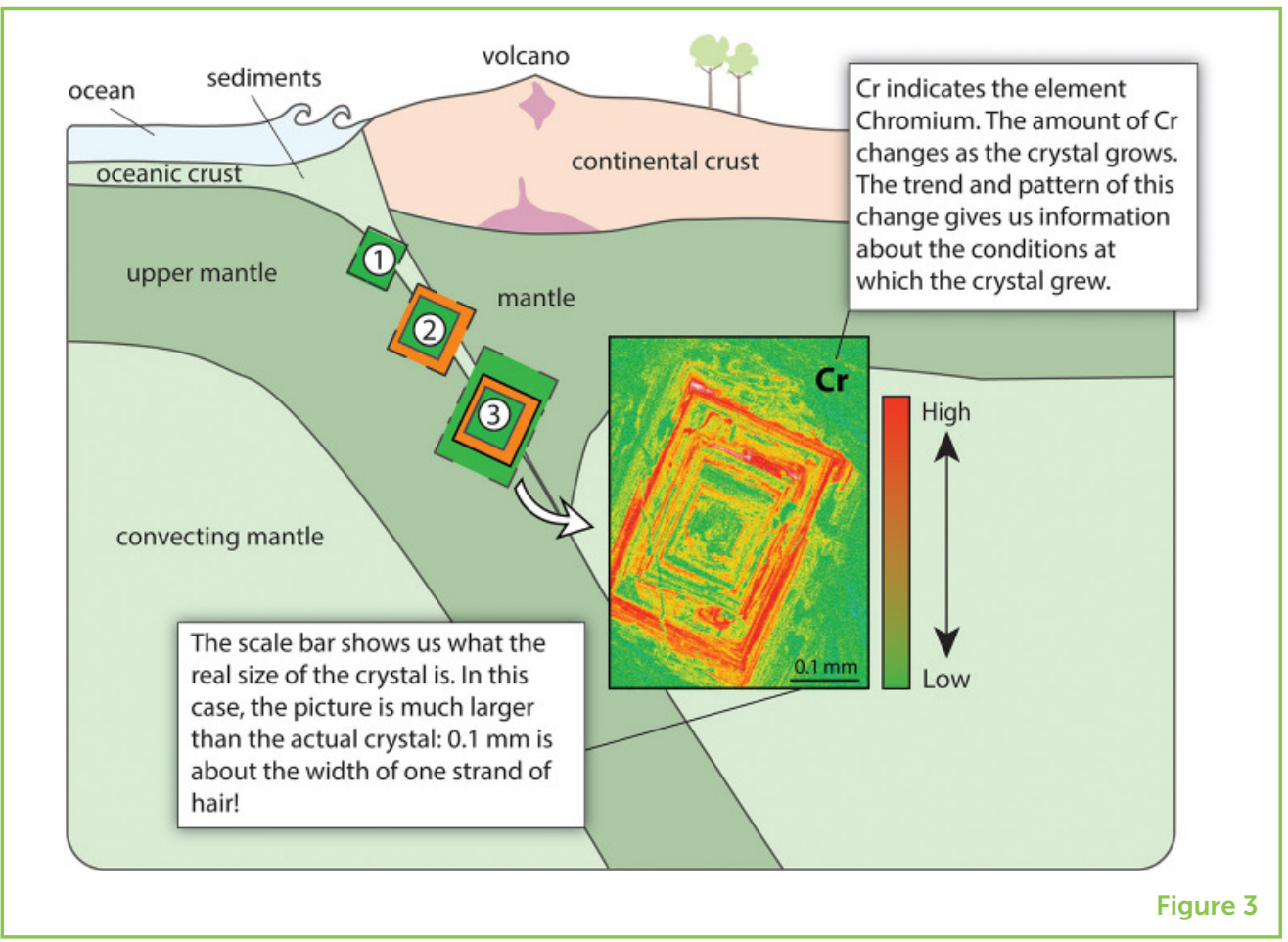

lawsonite crystal might indicate that a fluid containing dissolved chromium interacted with the lawsonite crystal at certain times, but not at other times (Figure 3). We can try to figure out where possible sources of chromium in the deep Earth recycling factory might be, such as the hot, dense rock called the mantle, which is located directly above the subducted plate.

Why would the amount of chromium have fluctuated as the lawsonite crystal grew? Geochemists do not yet know the answer to this question. One idea is that pulses of fluid move through the rock when there is an earthquake deep in the Earth. If this is true, then lawsonite composition and zoning is a record of dramatic chemical and physical processes that occurred in the Earth's past.

\section{SUMMARY}

Life on Earth is possible because of the recycling of water and elements through the tectonic plate system. As plates subduct, elements from the Earth's surface move to the interior of the planet in minerals. When these minerals break down, the released elements make their way to the Earth's surface through magma and gases that erupt at volcanoes. Studying the composition of minerals such as lawsonite is important because we can discover more about the recycling process that takes place deep underground where we can not see it directly.

How the Earth recycles affects the composition of the Earth's rocks, air, and ocean. If the Earth recycled faster or slower-or not at all-the 
planet would look very different. For the same reason, minerals that make up the outermost solid layer of the Earth, called the crust, would have different compositions depending on the recycling process. These minerals are the raw materials for technology, medicine, agriculture, and many other uses. For example, a mineral like copper is used in coins and electrical wire. Just like vitamins, calcium, and iron are important nutrients for your body and also for plant growth. No matter where you are when you read this article, you are using and surrounded by minerals, a result of the ongoing recycling process of our planet.

\section{ORIGINAL SOURCE ARTICLE}

Whitney, D. L., Fornash, K. F., Kang, P., Ghent, E. D., Martin, L., Okay, A.l., et al. 2020. Lawsonite composition and zoning as tracers of subduction processes: a global review. Lithos 370-1:105636. doi: 10.1016/j.lithos.2020.105636

\section{REFERENCES}

1. Hacker, B. R., Abers, G. A., and Peacock, S. M. 2003. Subduction factory-1. Theoretical mineralogy, densities, seismic wave speeds, and $\mathrm{H}_{2} \mathrm{O}$ contents. J Geophys Res Solid Earth. 108:2029. doi: 10.1029/2001JB001127

2. van Keken, P. E., Hacker, B. R., Syracuse, E. M., and Abers, G. A. 2011. Subduction factory-4. Depth-dependent flux of $\mathrm{H}_{2} \mathrm{O}$ from subducting slabs worldwide. J Geophys Res Solid Earth 115:B01401. doi: 10.1029/2010JB007922

3. Zack, T., Rivers, T., Brumm, R., and Kronz, A. 2004. Cold subduction of oceanic crust: implications from a lawsonite eclogite from the dominican Republic. Euro J Mineral. 16:909-16. doi: 10.1127/0935-1221/2004/0016-0909

4. Whitney, D. L., and Davis, P. B. 2006. Why is lawsonite eclogite so rare? Metamorphism and preservation of lawsonite eclogite, Sivrihisar, Turkey. Geology. 34:473-6. doi: 10.1130/G22259.1

5. Whitney, D. L., Fornash, K. F., Kang, P., Ghent, E. D., Martin, L., Okay, A.I., et al. 2020. Lawsonite composition and zoning as tracers of subduction processes: a global review. Lithos 370-1:105636. doi: 10.1016/j.lithos.2020.105636

SUBMITTED: 27 August 2020; ACCEPTED: 27 September 2021; PUBLISHED ONLINE: 01 November 2021.

EDITED BY: Noemie Ott, Swiss Federal Laboratories for Materials Science and Technology, Switzerland

CITATION: Newville C, Whitney DL, Kang P, Raia NH and Fornash KF (2021) How the Earth Recycles. Front. Young Minds 9:599596. doi: 10.3389/frym.2021.599596

CONFLICT OF INTEREST: The authors declare that the research was conducted in the absence of any commercial or financial relationships that could be construed as a potential conflict of interest. 

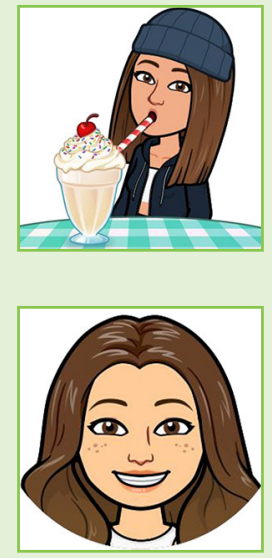

\section{MAYA, AGE: 13}

Hello, my name is Maya and I love to play sports like: Volleyball, golf, swimming, and more. I also love math and science. I have always been good at both of subjects and I find them both very fascinating. I also love to hang out with my family, friends, and my loving cat.

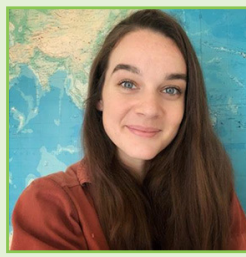

\section{AUTHORS}

\section{CHRISTINE NEWVILLE}

I am a master's student at the University of Minnesota, currently learning about rock deformation. I am curious about how folds, melt patterns, and mineral textures all record distinct aspects of rock deformation. In addition to geology, my favorite thing is to be involved with public science outreach, to find ways to bring current science into the hands of our communities. In my free time, I like to read science fiction. *newvi017@umn.edu

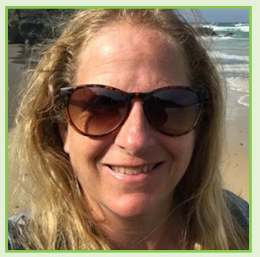

\section{DONNA L. WHITNEY}

I am a professor in the Department of Earth and Environmental Sciences at the University of Minnesota, where I teach and do research focused on how tectonics has transformed the planet over geologic time. I am particularly interested in analyzing metamorphic rocks to understand the chemical and physical processes that happen deep in the crust during tectonic processes, such as when mountains form and then collapse or when tectonic plates subduct and then pieces of them return to the Earth's surface. I love doing field work to study and collect rocks, and then bringing the rocks back to the lab to analyze mineral composition, structure, and age.

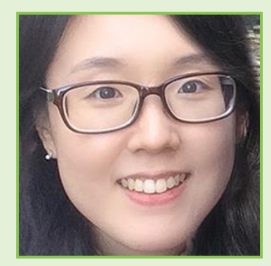

\section{PATRICIA KANG}

I am a Ph.D. student at the University of Minnesota, studying minerals in metamorphic rocks, which were once deeply subducted and brought back to the Earth's surface. 

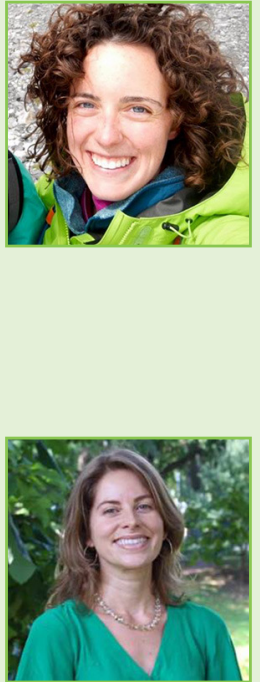

My research interests lie in applying various microscale analyses to track fluid-rock interactions recorded in the compositions of minerals. I love spending time in the lab taking microscale images of rocks that show interesting features invisible to the naked eye, such as tiny vapor bubbles and fluid inclusions trapped in minerals.

\section{NATALIE H. RAIA}

I am a Ph.D. student at the University of Minnesota, studying rocks that have been pushed deep into the earth and returned by plate tectonic processes. I am specifically interested in the movement and chemical composition of fluids at these great depths within the Earth and enjoy trying to decode the stories of rocks by studying them in the field and the lab. When I am not researching rocks, I enjoy learning about the museum field-how to manage scientific collections, create exhibits, and engage with the public to highlight exciting ongoing science.

\section{KATHERINE F. FORNASH}

I am an assistant professor in the Department of Geological Sciences at Ohio University. My research focuses on understanding the geologic processes that occur at convergent plate margins, which are places on Earth where two tectonic plates collide. To study these processes, I examine the chemistry and structures of high-pressure metamorphic rocks and minerals collected from ancient subduction zones around the world. 